\section{Use of Edible Coating to Preserve Pecans at Room Temperature}

\author{
Elizabeth A. Baldwin ${ }^{1}$ \\ U.S. Department of Agriculture, Agricultural Research Service, Citrus and \\ Subtropical Products Laboratory, Winter Haven, FL 33881
}

\author{
Bruce Wood \\ U.S. Department of Agriculture, Agricultural Research Service, Southeastern \\ Tree Nut Research Laboratory, Byron, GA 31008
}

Additional index words. Carya illinoinensis, flavor, oxidation, rancidity, storage, hexenal

\begin{abstract}
Unsaturated fatty acid oxidation results in rancid off-flavors in pecan [Carya illinoinensis(Wangenh.) K. Koch] kernels, which shortens shelf life under ambient conditions. For this reason kernels are stored under costly refrigeration. Edible coatings [hydroxypropyl cellulose (HPC) and carboxymethyl cellulose (CMC), plus various additives] were used to restrict oxygen contact with kernel associated fats by acting as a barrier to gas exchange. Fresh pecans were acquired from orchards, air-dried, shelled, and treated with various coating formulations. The kernels were then drained, dried, and stored several months in open air or perforated zip-lock plastic bags at 20 to $25^{\circ} \mathrm{C}$ and periodically evaluated by 18 to 20 sensory panelists using a 9-point hedonic scale for appearance, shine, off-flavor or overall flavor, and texture. Coated kernels generally scored lower for off-flavor, and higher for overall flavor. Preliminary coatings resulted in a less preferred appearance, but modifications to formulations of subsequent coatings resulted in either improved appearance or had no effect on appearance of kernels compared with uncoated control. Coatings with CMC imparted a shine to coated kernels, but did not generally affect texture. Hexanal accumulation, a good indicator of rancidity, of the homogenate of kernels stored at ambient temperatures for 5 and 9 months was lower in kernels coated with $\mathrm{CMC}$ than in the uncoated control, with CMC coatings including $\alpha$-tocopherol being most effective. Thus, CMC-based coatings exhibit potential for extending the shelf life of pecan kernels.
\end{abstract}

Pecan (Caryaillinoinensis) kernels contain high quantities of unsaturated fatty acids, which are subject to oxidative cleavage. This results in the development of rancid off-flavors, which can render kernels unmarketable. Pecans usually have a shelf life of 10 weeks at 21 to 24 ${ }^{\circ} \mathrm{C}$ (Wells and Barber, 1959), and 9 months at 4.4 to $7.2{ }^{\circ} \mathrm{C}$ [National Pecan Shellers' Association (NPSA), 1997]. Pecans are, therefore, stored at low or freezing temperatures, thus imparting considerable expense to storage, shipping, and marketing. Retail distribution and marketing is usually at relatively high ambient temperatures, which promotes development of off-flavors.

Pecan kernels likely begin to oxidize at ripening with the process increasing and accelerating as time passes. The oxidation process accelerates after shelling, so unless frozen, the degree of rancidity is greater in kernels that have been shelled than in kernels still in the nut. Because kernels are not sold frozen, all kernels purchased by consumers exhibit a degree of lipid oxidation (rancidity) and, thus,

Received for publication 29 June 2005. Accepted for publication 13 Sept. 2005. Mention of a trademark or proprietary product is for identification only and does not imply a guarantee or warranty of the product by the U.S. Department of Agriculture. The U.S. Department of Agriculture prohibits discrimination in all its programs and activities on the basis of race, color, national origin, gender, religion, age, disability, political beliefs, sexual orientation, and marital or family status.

${ }^{1}$ To whom reprint requests should be addressed; e-mail ebaldwin@citrus.usda.gov. some off-flavor. Any method to retard this oxidation process would improve the quality of commercial pecan kernels.

The development of rancid off-flavors is affected by storage temperature, oxygen concentration, moisture content, and presence of polyunsaturated fatty acids. Shelled pecan kernels contain from $3.4 \%$ to $4 \%$ moisture (percent wet basis) (Senter and Forbus, 1979), and $55 \%$ to $70 \%$ lipids (Wood and McMeans, 1982; Worley, 1994), although fully developed kernels should have $70 \%$ lipids. Unsaturated lipids in the presence of oxygen form alkyl and peroxyl radicals, which propagate hydroperoxides (Frankel, 1991). Pecan lipid classes are mono-, di-, and tri-acylglycerols, free fatty acids and phospholipids (Santerre, 1994). The oils are predominantly triglycerides primarily composed of $\mathrm{C}_{18}$ unsaturated fatty acids, including at least 23 fatty acids (Senter and Horvat, 1978). This results in a high degree of unsaturation (90\%) with 54\% to $65 \%$ monounsaturated, and $25 \%$ to $34 \%$ polyunsaturated lipids (Duke, 1989; Maness et al., 1995; NPSA, 1997). The induction period and oxidation rates of fatty acids found in lipids at ambient temperatures are shortest and fastest, respectively, for polyunsaturated lipids such as linoleic $(18: 29,12)$ and linolenic $(18: 39$, $12,15)$ compared with saturated (stearic acid) or monounsaturated (oleic acid) lipids (Belitz and Grosch 1987; Coultate, 1989; Nawar, 1996). Products of oxidation include volatile aldehydes (hexanal among others), alcohols, ketones and hydrocarbons. These compounds likely contribute to the rancid flavor (Frankel,
1991; Gray, 1978) resulting in descriptors such as grassy-green, painty-solvent, cardboard, and metallic (Civille and Dus, 1992; Johnson etal., 1988). Hexanal levels and peroxide values are often used as a measure of lipid oxidation or rancidity in kernels as hexanal concentrations are found to be in agreement with sensory ratings for rancidity (Kanamangala et al., 1999). Development of rancidity involves hydrolysis of glycerides into free fatty acids, oxidation of double bonds of unsaturated fatty acids to form peroxides and ultimately autooxidation of the free fatty acids.

Edible coatings have been used to decrease rancidity of kernels, by providing a barrier to oxygen and moisture, and to improve appearance by adding gloss. Zein coatings extended the shelf-life and reduced rancidity of kernels and nut clusters in chocolate bars (Cosler, 1957, 1958a, 1958b), but did not reduce rancidity of almonds in chocolate confectionery products (Harris, et al., 1972). Caseinate and gelatin coatings limited oxidative rancidity and prevented sticking of nuts in bakery items (Durst, 1967). Whey protein actually enhanced oxidation due to oil leakage in walnuts (Mate and Krochta, 1997), but reduced hexanal and peroxides (products of oxidative rancidity) in peanuts. Whey protein isolate increased gloss of peanuts and hazelnuts, and decreased rancidity of peanuts (Krochta, personal communication). Bilayer coatings of whey protein and acetylated monoglycerides reduced oxidation of walnuts, while acetylated monoglyceride coatings reduced sogginess of chopped almonds (Adams et al., 1995), resulted in a small decrease in rancidity of pecans (Senter and Forbus, 1979), and extended shelf life of walnut pieces (Mata and Krochta, 1997). Acetylated monoglyceride coatings combined with tertiary butylhydroquinone (TBHQ, an antioxidant), and citric acid inhibited carbonyl production (indicator of rancidity) in peanuts (Hoover and Nathan, 1981).

All of the above coatings are protein-based except for the acetylated monoglycerides, which are lipid-based. In this study, we assessed the efficacy of certain polysaccharidebased materials for reduction of rancidity of shelled pecan kernels during ambient storage conditions. We report here that certain cellulose derivatives formulated with plasticisers, surfactants, acidulants and antioxidants reduce the rancidity of shelled pecan kernels at ambient storage conditions.

\section{Materials and Methods}

Fresh, shelled pecans ('Desirable') were acquired from the U.S. Southeastern Tree Nut Research Laboratory, Byron, Ga., over three crop seasons. Kernels originated from a drip irrigated 'Desirable' orchard of approximately 20-year-old trees. The 'Desirable' trees were mechanically harvested (i.e., mechanically shaken, wind-rowed, and mechanically picked up within 2 to $3 \mathrm{~d}$ of shaking) in late October. The harvesting operation and timing is typical of commercial pecan farming operations. Nuts were then cleaned in a commercial cleaning facility and there sorted to blow out 
Table 1. Pecan coating treatments $(\mathrm{MC}=$ methylcellulose, $\mathrm{CMC}=$ carboxymethyl cellulose, $\mathrm{HPC}=$ hydroxypropyl cellulose, $\mathrm{PG}=$ propylene glycol, $\mathrm{BHA}=$ butylated hydroxanisole, BHT = butylated hydroxytoluene).

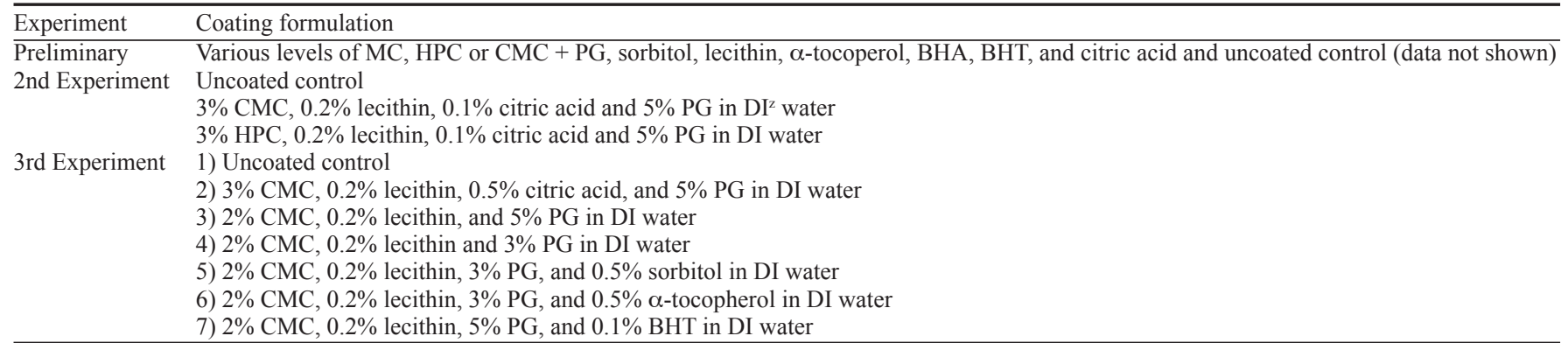

${ }^{\mathrm{2}} \mathrm{DI}=$ deionized water.

poorly filled nuts in preparation for commercial marketing. They were then bagged and placed in cold storage until shelling. Nuts for eventual study were randomly selected from cleaned and bagged nuts about 2 weeks after harvesting. After shelling, kernels were placed in plastic zip-lock bags and again retained in cold storage until shipping for experimentation. Kernels were of high quality and originated from well-filled nuts.

Kernels for experimentation were then coated by dipping for $30 \mathrm{~s}$, drained, and airdried. The coated and uncoated kernels were stored in open air or in zip-lock bags ( 7 bags with $250 \mathrm{~g}$ kernels/bag) with four $1-\mathrm{mm}$ holes to allow entrance of oxygen. All kernels were stored at 20 too $25^{\circ} \mathrm{C}$, periodically evaluated by taste panels and, in some cases, analyzed for color and hexanal levels during storage.

Apreliminary experiment was conducted in the first season, to determine which cellulose derivative (methylcellulose $=\mathrm{MC}$; hydroxypropyl cellulose $=$ HPC; or carboxymethyl cellulose $=$ CMC; Aqualon, Wilmington, Del.) would be most effective in extending pecan shelf life. After determining that HPC and CMC were most promising, based on informal taste tests and adherence of coating to the kernels, subsequent experiments were conducted with these film formers (Table 1). Other additives were combined with the cellulose film formers including propylene glycol (PG) and sorbitol, plasticizers, which are compounds that are added to coatings to increase flexibility, and lecithin, a surfactant and emulsifier, which are surface-active agents and macromolecular stabilizers, respectively (Cuppett, 1994). These latter compounds allow adherence and mixing of hydrophobic and hydrophilic materials. Also added to coating formulations were $\alpha$-tocopherol (vitamin E), butylated hydroxyanisole (BHA), and butylated hydroxytoluene (BHT), antioxidants which inhibit the free-radical autoxidation process (Sherwin, 1990). We also used an acidulant-chelator, citric acid (Dorres, 1990). All chemicals were purchased from Sigma-Aldrich Co (St. Louis, Mo.). Kernels from the second and third experiments were treated as indicated in Table 1.

For sensory analyses, 18 to 20 panelists were given three kernels (technically one cotyledon or kernel) per treatment to rate for appearance and overall flavor (preference), as well as texture (crispness rating), off-flavor (intensity) on a 9-point hedonic scale ( $1=$ dislike and $9=$ like extremely) for preference and a 9 -point category scale $(1=$ low and $9=$ high in intensity) for intensity ratings, and soft to crisp for texture ( $1=$ soft and $9=$ more crisp). Panelists were asked to taste kernels and rate texture and flavor in a booth equipped with red light, then to observe 6 to 10 kernels placed on plates arranged on a table for appearance and shine in a well-lit area. With a few exceptions, the panelists were the same from year to year. Panelists had been involved in previous pecan experiments, were accustomed to rating pecan kernels and, therefore, were considered experienced.

For chemical and physical analysis in the second experiment, 10 other kernels from the same treatment were homogenized with an equal weight of water. In total, $2 \mathrm{~mL}$ of the homogenate was transferred to 6-mL GC vials with crimp-top caps and seals, frozen in liquid $\mathrm{N}_{2}$ and stored at $-20^{\circ} \mathrm{C}$, pending analysis. Hexanal levels were determined using a method developed for tomato (Baldwin et al., 1998) with some modifications. Headspace of each of three sample homogenates (10 pecans/homogenized sample) was analyzed using a gas chromatograph equipped with a headspace sampler (model HS-6; Perkin Elmer), a $0.53 \mathrm{~mm} \times 30$ $\mathrm{m}$ polar column $(1.0-\mu \mathrm{M}$ film thickness, Stabilwax, Restek Corp., Bellefonte, Pa.) and a flame ionization detector. Concentrations were calculated using regression equations, determined by injecting five concentrations of a hexanal standard in fresh pecan homogenate (fresh nonrancid

Fig. 1. (top) Appearance rating by experienced panelists $(0=$ least preferred appearance, $10=$ most preferred appearance) and (bottom) shine rating by experienced panelists $(0=$ low shine, $10=$ high shine) for uncoated (control), or coated (hydroxypropyl cellulose, HPC or carboxymethyl cellulose, CMC coatings) kernels stored 4 and 8 months at ambient temperature. Data are means for 18 panelists, means separation by LSD at $P \leq 0.05$. kernels) to obtain a peak height calibration curve. Color analysis was performed using a chromameter (model CR-200; Minolta, Ramsey, N.J.) calibrated with a white tile (L* $\left.=97.7, a^{*}=-0.43, b^{*}=1.92\right)$, using the $\mathrm{L}^{*}$ coordinate, and the instrument-calculated hue angle. Measurements were made three times on the ventral side of each of 10 kernels per treatment.

SAS version 8 (SAS Institute, Cary, N.C.) was used for analysis of data. Sensory flavor, appearance, visual shine, hexanal and texture
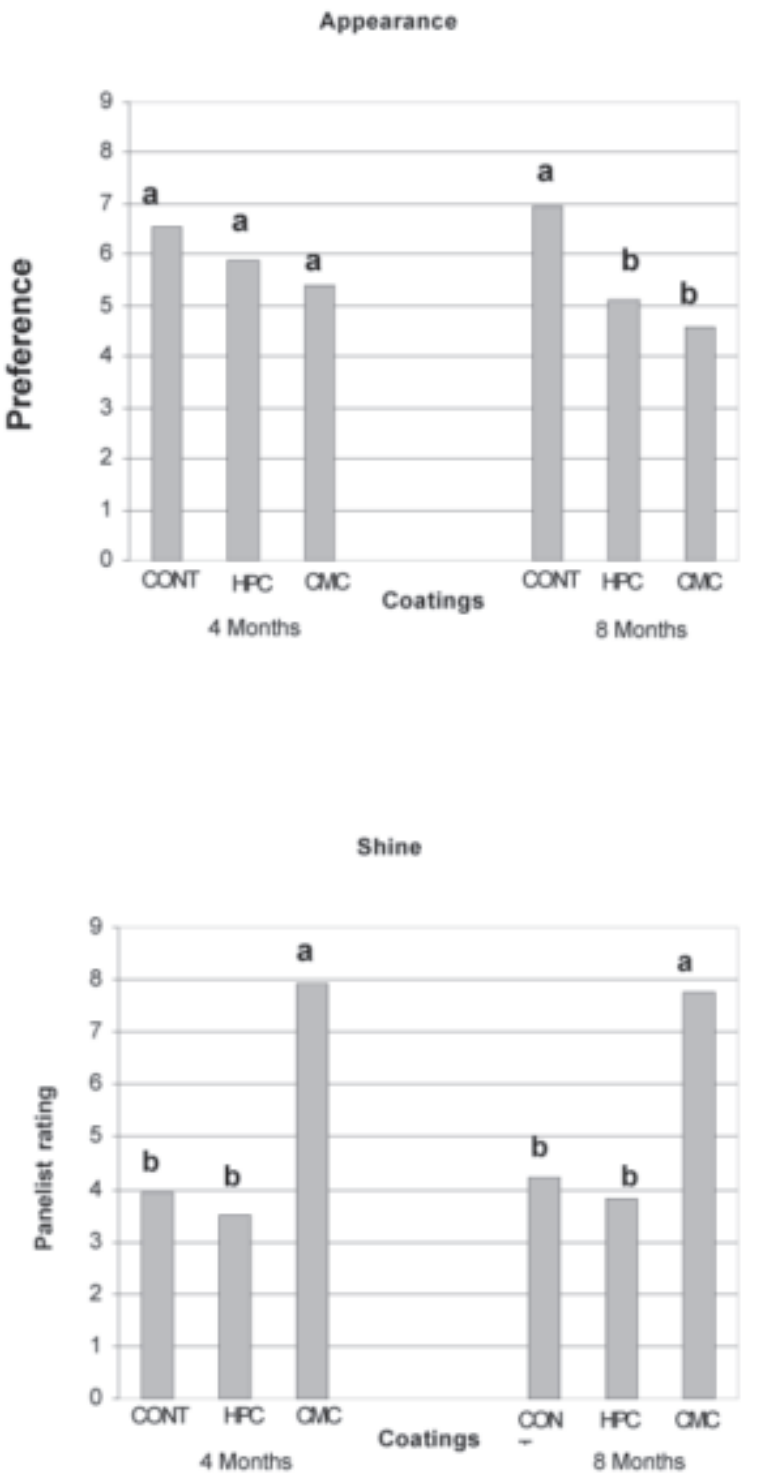
data were analyzed using analysis of variance (PROC GLM) with each panelist considered as a replication, and mean separation was by least significant difference (LSD) at $\mathrm{P} \leq 0.05$.

\section{Results and Discussion}

In preliminary work, kernels were coated with MC, HPC, or CMC with added lecithin, citric acid, BHA, BHT, and PG. After 10 months of open air, ambient storage, the kernels were observed and tasted by an informal fivemember panel. The controls tasted the most

\section{Off-flavor}
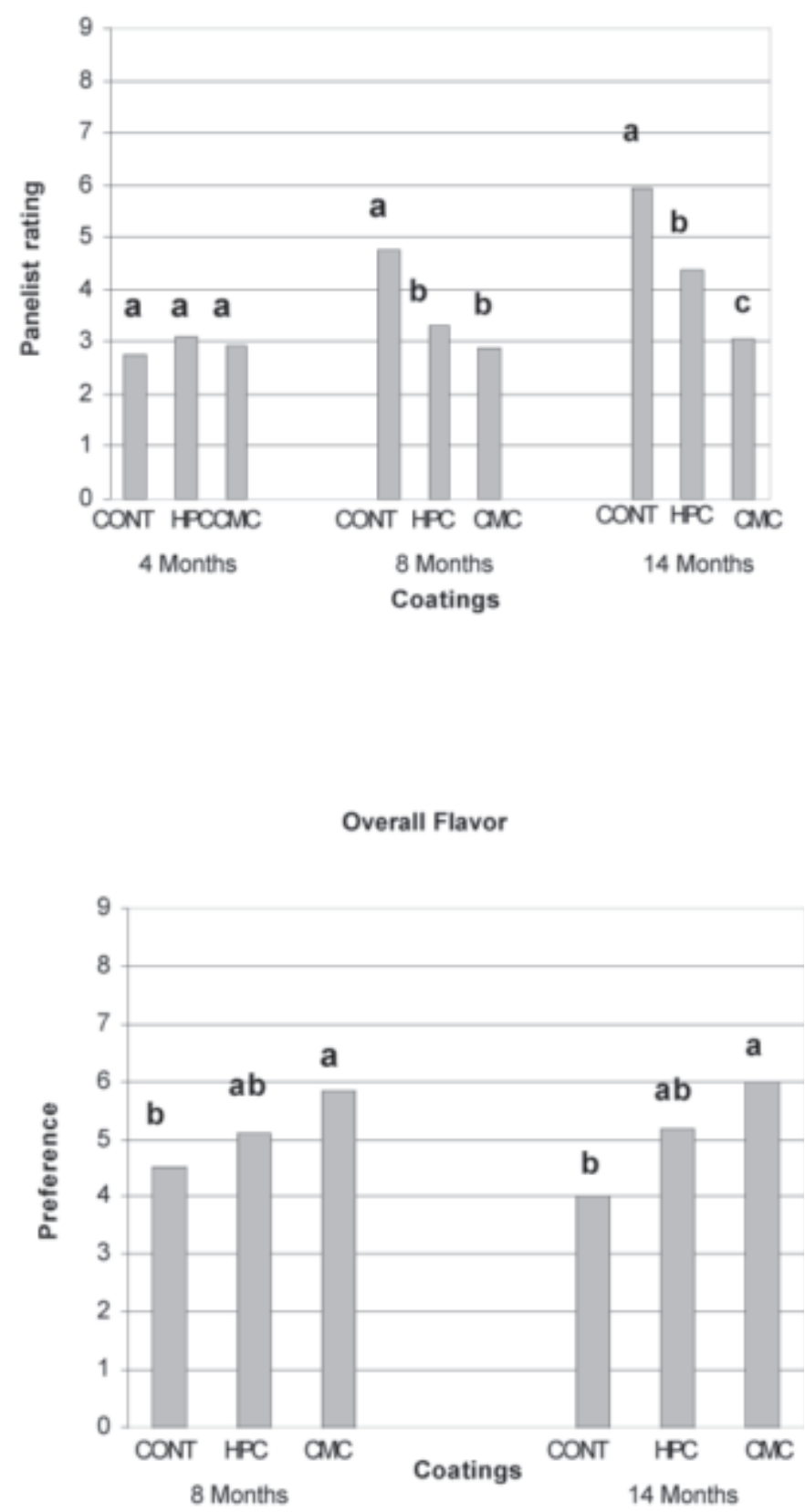

Fig. 2. (top) Off-flavor rating ( $0=$ no off-flavor, $10=$ high off-flavor $)$ and (bottom $)$ overall flavor rating $(0=$ least preferred flavor, $10=$ most preferred flavor) by experienced panelists under red light for uncoated (control) or coated (hydroxypropyl cellulose, HPC or carboxymethyl cellulose, CMC coatings) kernels stored 4 to 14 months at ambient temperature. Data are means for 18 panelists, means separation by LSD at $P \leq 0.05$. rancid, followed by the $\mathrm{MC}$-coated kernels. The HPC-coated kernels tasted only slightly rancid and the $\mathrm{CMC}$-coated kernels did not have any rancid flavor at all (data not shown). There was some flaking of the MC coating, while HPC and CMC coatings added gloss (shine) to the kernels, however the kernels looked dark in appearance. In subsequent experiments HPC and/or CMC were used for coatings at various concentrations and with various additives.

In the second experiment, coated (HPC or $\mathrm{CMC}$ with additives) and uncoated kernels were stored in perforated plastic bags at ambient temperature for up to 8 months. All coated kernels were less preferred in appearance by the panelists due to a darkening of the coated kernels by 8 months of storage (Fig. 1 top), even though the $\mathrm{CMC}$ coating imparted a definite shine to the kernels (Fig 1 bottom). One panelist, however commented that the kernels were too glossy. Both coatings reduced off-flavor compared with controls (2-fold lower scores for CMC), and $\mathrm{CMC}$ improved overall flavor after 8 to 14 months of storage (Fig. 2 top and bottom, respectively). Control, uncoated kernels elicited comments like not fresh, old, stale and rancid from panelists. Coated kernels resulted in comments like fruity flavor, dark color, and one panelist noted slick mouth-feel.

In the third experiment, only CMC was used as the film former with various additives and the kernels stored in perforated plastic bags for up to 11 months. Seven coating formulations were evaluated, consisting of CMC with various additives. Only four of the treatments are shown (treatment numbers $1,4,5$, and 6),
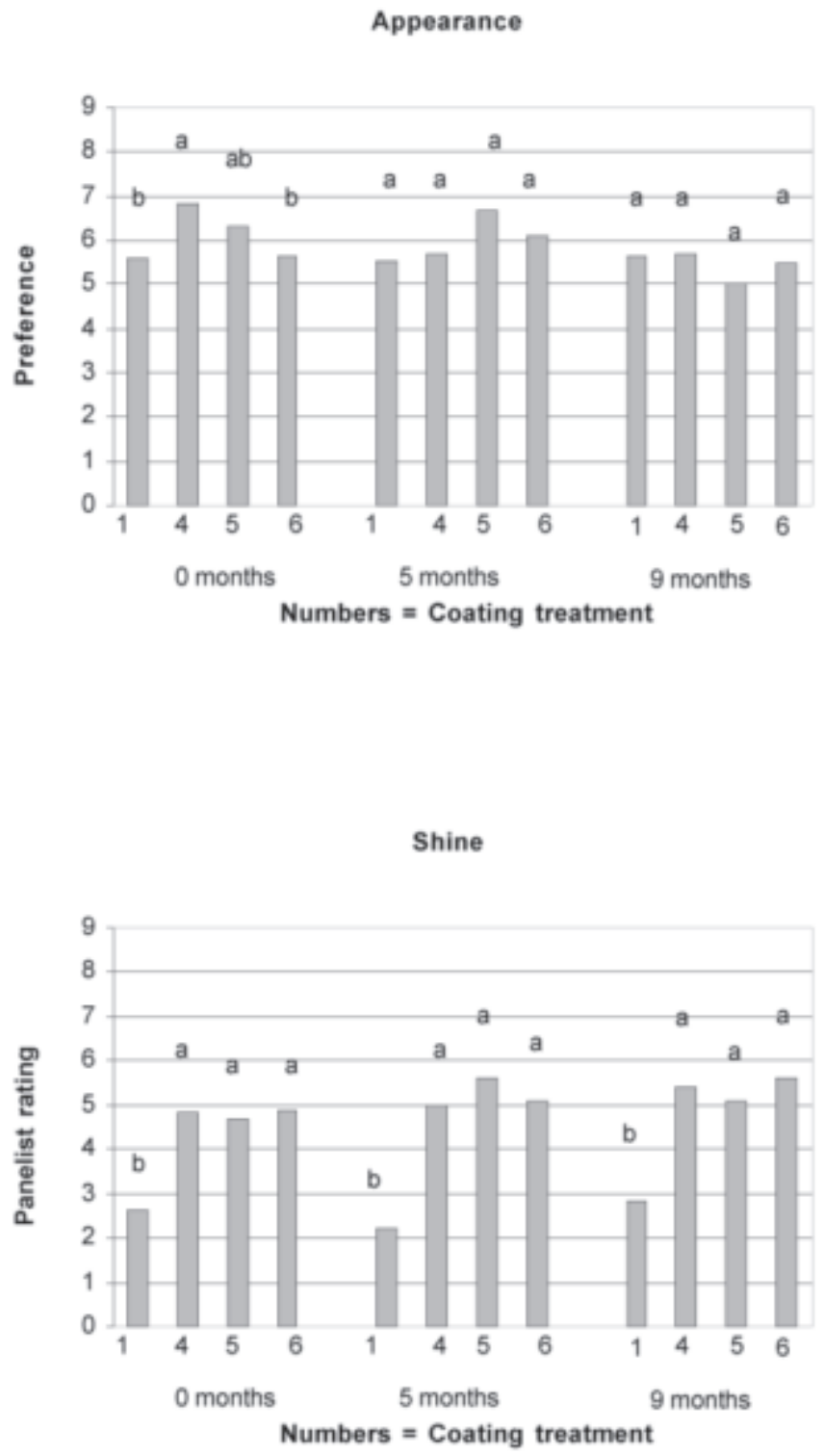

Fig. 3. (top) Appearance rating by experienced panelists $(0=$ least preferred appearance, $10=$ most preferred appearance) and (bottom) shine rating by experienced panelists $(0=$ low shine, $10=$ high shine $)$ for uncoated (control), or CMC-coated (treatments 4, 5, and 6 are CMC coating with different additives) kernels stored 0 and 9 months at ambient temperature. Data are means for 18 panelists, means separation by LSD at $P \leq 0.05$. 
Table 2. Color of uncoated (treatment 1) and coated (treatments 4 to 6) pecan kernels stored in perforated zip-lock bags for 5 and 11 months at 20 to $25^{\circ} \mathrm{C}$. Data are an average \pm SD for 10 nuts per treatment.

\begin{tabular}{|c|c|c|c|c|}
\hline \multirow[b]{3}{*}{ Treatment $^{2}$} & \multicolumn{4}{|c|}{ Pecan kernel color } \\
\hline & \multicolumn{2}{|c|}{5 months } & \multicolumn{2}{|c|}{11 months } \\
\hline & $\mathrm{L}^{*}$ & ${ }^{\circ} \mathrm{Hue}$ & $\mathrm{L}^{*}$ & ${ }^{\circ} \mathrm{Hue}$ \\
\hline$\overline{1}$ & $36.6 \pm 3.2$ & $58.9 \pm 4.8$ & --- & --- \\
\hline 4 & $34.6 \pm 2.0$ & $54.2 \pm 3.8$ & $31.1 \pm 1.6$ & $46.8 \pm 3.9$ \\
\hline 5 & $34.4 \pm 3.2$ & $53.0 \pm 4.5$ & $33.1 \pm 3.4$ & $50.7 \pm 6.7$ \\
\hline 6 & $36.9 \pm 2.3$ & $56.5 \pm 3.3$ & $32.8 \pm 3.2$ & $49.1 \pm 4.8$ \\
\hline
\end{tabular}

${ }^{2}$ Treatment 1 was uncoated control; treatment 4 was $2 \%$ CMC, $0.2 \%$ lecithin, and $3 \%$ PG; treatment 5 was $2 \%$ CMC, $0.2 \%$ lecithin, $3 \%$ PG, and $0.5 \%$ sorbitol; treatment 6 was $2 \%$ CMC, $0.2 \%$ lecithin, $3 \%$ PG; and $0.5 \%$ tocopherol. Controls (i.e., treatment 1 ) exhibited fungal growth after 10 months of storage and had to be eliminated.

as the others (treatments numbers 2,3, and 7) did not show an improvement compared with controls (treatment 1) due to some flaking of the coating probably resulting in less restriction of oxygen, and therefore, no differences in flavor.

Results showed an initial preference for appearance of coated fruit (Fig. 3 top), but there were no differences in preference for appearance after 5 or 9 months of storage, even though the CMC coated kernels exhibited added shine(Fig. 3 bottom). Visually, there was less darkening of the kernels with the coating treatments this time,

after 5 months of storage, and no darkening of kernels from treatment 6 , as was evident from the L* (lightness) as well as hue angle (color), where higher values correlated with lighter brown color (Table 2). However after 11 months of storage, controls exhibited fungal growth and coated kernels had darkened, as evidenced by lower $L^{*}$ values and hue angle compared with the 5 month data.

Coated kernels initially had slightly higher off-flavor, perhaps due to the coating itself, but had less off flavor and better overall flavor after 9 months of storage (Fig. 4 top and bottom, respectively). In support of the sensory data, analysis of pecan slurry by gas chromatography revealed that hexanal levels were less by at least 2-fold in coated kernels (treatments 4,5 , and 6) compared with uncoated controls (treatment 1) after 5 months of storage, and in

\section{Hexanal levels}

a
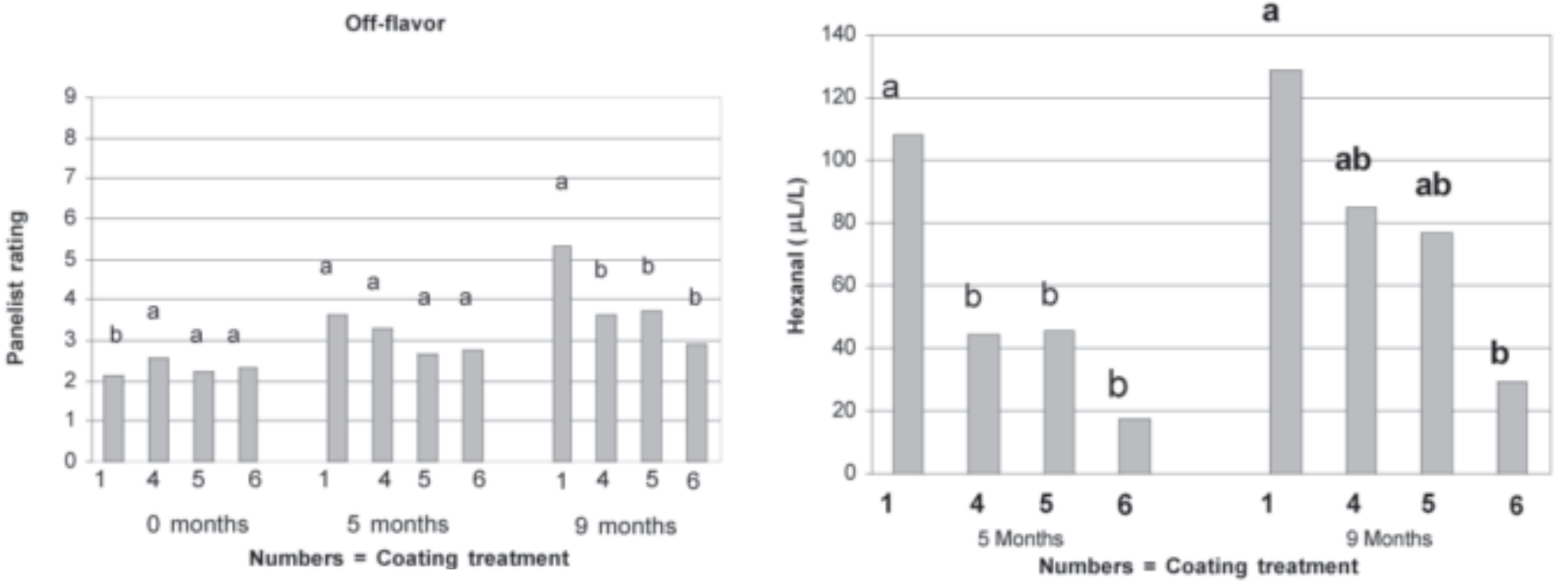

Numbers = Coating treatment

Overall flavor

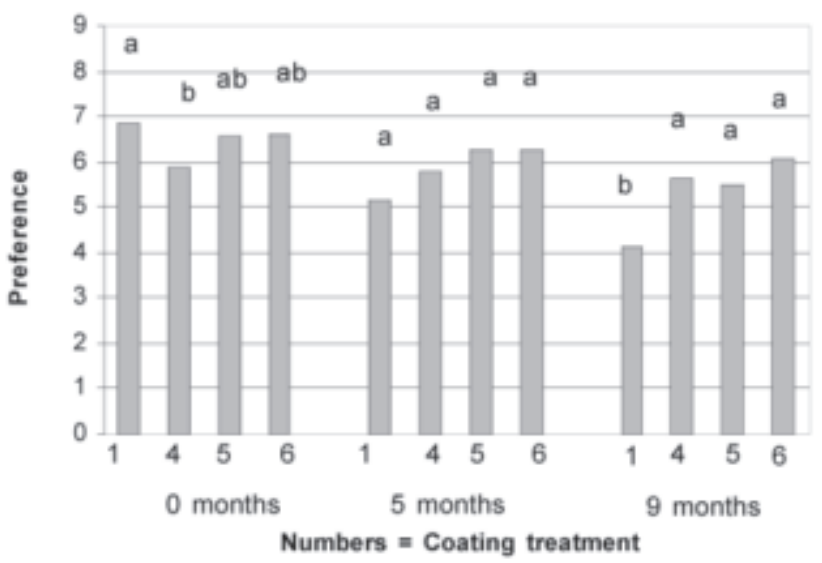

Fig. 4. (top) Off-flavor rating $(0=$ no off-flavor, $10=$ high off-flavor $)$ and (bottom) overall flavor rating $(0=$ least preferred flavor, $10=$ most preferred flavor) by experienced panelists under red light for uncoated (control) or CMC-coated (treatments 4, 5, and 6 are CMC coating with different additives) kernels stored 0 and 9 months at ambient temperature. Data are means for 18 panelists, means separation by LSD at $P \leq 0.05$..

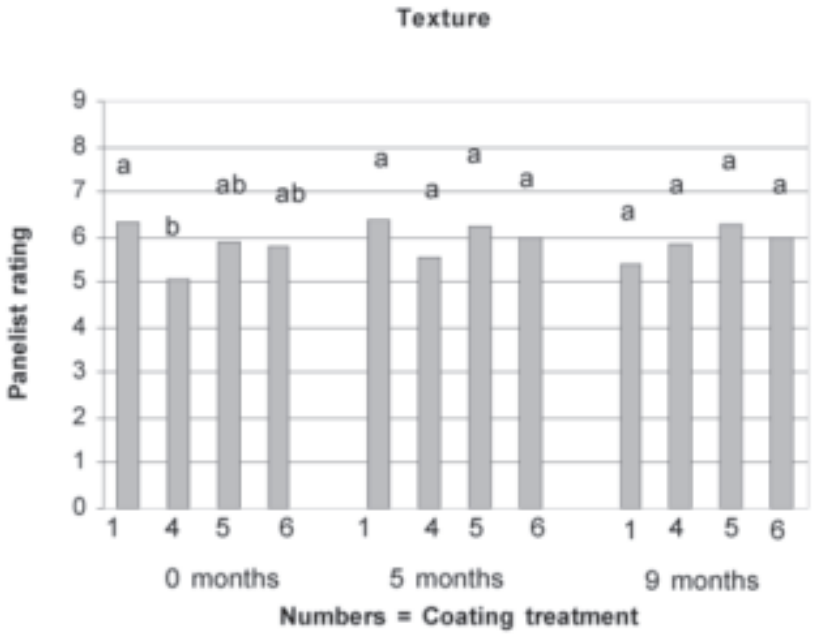

Fig 5. (top) Hexanal levels in pecan homogenate from and (bottom) texture of nuts $(0=$ most soft, $10=$ most crisp) uncoated (control) or CMC-coated (treatments 4, 5, and 6 are CMC coating with different additives) intact kernels stored 0 and 9 months at ambient temperature. For hexanal, data are means of three replicate samples, each a composite of 10 nuts; and for texture, data are means of 20 panelists, means separation by LSD at $P \leq 0.05$. 
kernels from treatment 6 by about 4 -fold, with the added $\alpha$-tocopherol, after 9 months (Fig. 5 top). This indicates that the kernels with lower hexanal levels underwent less oxidation of fats, and were less rancid, as was indicated by the sensory analysis. There were generally no differences in texture (Fig. 5 bottom).

Pecan kernel lipids begin to oxidize at ripening, which accelerates after shelling. Unless frozen, the degree of rancidity increases with shelf life leading to off-flavor. Freezing is expensive during storage, and the kernels are not sold frozen. Therefore, coating the kernels could possibly reduce or eliminate the need for freezing and would reduce lipid oxidation (i.e., rancidity) during marketing at ambient temperature, by restriction of oxygen contact with the kernel lipids. This would reduce costs to the pecan industry and improve quality for the consumer.

Initially, darkening of the kernels was a problem, but this appeared to be related to the plasticizer, PG (used to prevent flaking of the coating), and was resolved by using 3\% instead of 5\% PG in coating formulations, with little negative effect on coating performance. Rancidity of the kernels, as evidenced by sensory analysis and hexenal levels, was reduced up to at least 9 months of storage at ambient temperature, especially in formulations that included $\alpha$-tocopherol (vitamin $\mathrm{E}$ ), which adds a nutritional component to the coating. In spite of the occasional comment about mouth-feel, differences in texture of the coated and uncoated kernels were generally not significant. These results indicate that shelf life of pecan kernels at ambient temperatures, typically encountered at the retail level, can be substantially extended by use of certain edible coating formulations.

\section{Literature Cited}

Adams, R.M., N. Melachouris, G. Tonner, and D.V. Vadehra. 1995. U.S. Patent 5,401,518.

Baldwin, E.A., J.W. Scott, M.A. Einstein, T.M.M. Malundo, B.T. Carr, R.L. Shewfelt, and K.S. Tandon. 1998. Relationship between sensory and instrumental analysis for tomato flavor. J. Amer. Soc. Hort. Sci. 123:906-915.

Belitz, H.-D. and W. Grosch. 1987. Food chemistry. Springer-Verlag, New York.

Civille, G.V. and C.A. Dus. 1992. Sensory evaluation of lipid oxidation in foods, p. 279-289. In: A.J. St Angelo (ed.). Lipid oxidation in food. Amer. Chem.Soc. Symp. Ser. 500.

Cosler, H.B. 1957. Method of producing zein-coated confectionery. U.S. Patent 2,791, 509.

Cosler, H.B. 1958a. Prevention of staleness and rancidity in nut meats and peanuts. Manuf. Confect. 37:15-18, 39-40.

Cosler, H.B. 1958b. Prevention of staleness, rancidity in nut meats and peanuts. Peanut J. Nut World $37: 10-11,15$.

Coultate, T. 1989. Food: the chemistry of its components. 2nd ed. Royal Soc. Chem., London, U.K.

Cuppett, S.L. 1994. Edible coatings as carriers of food additives, fungicides and natural antagonists, p. 121-137. In: J. Krochta, E.A. Baldwin, and M.O. Nisperos-Carriedo (eds.). Edible coatings and films to improve food quality. Technomic Publ. Co. Inc., Lancaster, Pa.

Dorres, S. 1990. pH control agents and acidulants, p. 477-510. In: A.L. Branene, P.M. Davidson, and S. Salinen (eds.). Food additives. Marcel Dekker, Inc., New York.

Duke, J.A. 1989. CRC handbook of nuts. CRC Press, Boca Raton, Fla.

Durst, J.R. 1967. Protective coatings. U.S. Patent 3,323,922.

Frankel, E.N. 1991. Recent advances in lipid oxidation. J. Sci. Food Agr. 54:495-511.

Gray, J.J. 1978. Measurement of lipid oxidation: a review. J. Amer. Oil Chemists Soc. 55:539-546.

Harris, N.E., D.E. Westcott, and A.S. Henick. 1972. Rancidity in almonds: Shelf-life studies. J. Food Sci. 37:824-827.

Hoover, M.W. and P.J. Nathan. 1981. Influence of tertiary butylhydroquinone and certain other surface coatings on the formation of carbonyl compounds in granulated roasted peanuts. $\mathrm{J}$ Food Sci. 47:241-248.

Johnson, P.B., G.V. Civille, J.R. Vercellotti, T.H.Sanders, C.A. Dus. 1988. Development of a lexicon for the description of peanut flavor. $\mathrm{J}$. Sensory Studies 3:9-17.

Kanamangala, R.V., N.O. Maness, M.W. Smith, G.H. Brusewitz, S. Knight, and B.Chinta. 1999. Reduced lipid pecans: Chemical alteration and implications for quality maintenance during storage. J. Amer. Soc. Hort. Sci.. 124:389-398.

Maness, N.O., D. Chrz, T. Pierce, and G.H. Brusewitz. 1995. Quantitative extraction of pecan lipid from small samples using supercritical carbon dioxide. J. Amer. Lipid Chem. Soc. 72:665-669.

Mate, J.I. and J.M. Krochta. 1997. Whey protein and acetylated monoglyceride edible coatings: effect on the rancidity process of walnuts. J. Agr. Food Chem. 45:2509-2513.

Nawar, W.W. 1996. Lipids, p. 225-320. In: O.R. Fennema (ed.). Food chemistry. 3rd ed. Marcel Dekker, New York.

National Pecan Shellers Association. 1997. A guide to the use of pecans in processed foods. Informational brochure. Natl. Pecan Shellers Assn. Atlanta, Ga.

Santerre, C.R. 1994. Pecan composition, p. 98-110. In: C.R. Santerre (ed.). Pecan technology. Chapman and Hall, New York.

Senter, S.D. and R.J. Horvat. 1978. Minor fatty acids from pecan kernel lipids. J. Food Sci. 43:1614-1615.

Senter, S.D. and W.R. Forbus, Jr. 1979. Effects of acetylated monoglyceride coatings on pecan kernel shelf-life. J. Food Sci. 44:1752-1755.

Sherwin, E.R. 1990. Antioxidants, p. 139-193. In: A.L. Branene, P.M. Davidson, and S. Salinen (eds). Food Additives. Marcel Dekker Inc, New York.

Wells, A.W. and H.R. Barber. 1959. Extending the market life of packaged shelled nuts. USDA, Agr. Mktg. Serv., Mktg. Res. Div. Mktg. Res. Rpt. 329.

Wood, B.W. and J.L. McMeans. 1982. Carbohydrates and fatty acids in developing pecan fruit. J.Amer. Soc. Hort. Sci. 107:47-50.

Worley, R.E. 1994. Pecan physiology and composition, p. 39-48. In: C.R. Santerre (ed.). Pecan technology. Chapman and Hall, New York. 